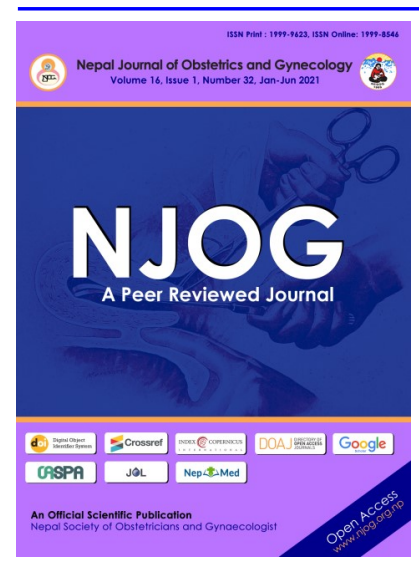

CORRESPONDENCE

Dr Tandin Tshomo

Khesar Gyalpo University of Medical science, Thimphu, Bhutan

Email:

tndn.tshomo@gmail.co $\mathrm{m}$;

Phone: +975-17735377

Received: July 20, 202

Accepted: May 1, 2021

\section{Citation:}

Tshomo T, Tenzin K, Tshering J. Awareness and perception of epidural labor analgesia among pregnant women visiting antenatal clinic in National Referral Hospital. Nep J Obstet Gynecol. 2021;16(32):10-15. DOI: https://

doi.org/10.3126/njog.v16i1 37410

\title{
Awareness and perception of epidural labor analgesia among pregnant women visiting ante-natal clinic in National Referral Hospital
}

\author{
Tandin Tshomo ${ }^{1,2}$, Karma Tenzin ${ }^{1}$, Jamphel Tshering ${ }^{2}$ \\ ${ }^{1}$ Khesar Gyalpo University of Medical Science, Thimphu, Bhutan \\ ${ }^{2}$ Jigme Dorji Wangchuck National Referral Hospital, Thimphu, Bhutan
}

\section{ABSTRACT}

Aims: To assess the awareness and perception of labour epidural analgesia among pregnant women visiting the antenatal clinic.

Methods: This was an observational cross-sectional study. Study participants included pregnant women visiting the antenatal clinic during 2 nd and $3^{\text {rd }}$ trimester conducted from $21^{\text {st }}$ September 2018 till $20^{\text {th }}$ September 2019. Data were collected by using an interviewer-administered questionnaire. Ethics approval was granted by the research Ethics Board of health, Bhutan.

Results: Total 450 parturients participated in this study; $61.4 \%$ of the participants knew that labour epidural services were available and $37.5 \%$ got information through media. A total of $57.3 \%$ of respondents had severe fear about labour pain; $62.4 \%$ had severe fear about delivery complication; $85.2 \%$ thought that epidural labour analgesia was a good method of pain relief; and $67 \%$ were willing to accept it for their current pregnancy. However, $86.6 \%$ would recommend epidural labour analgesia as an option of pain relief to other pregnant women.

Conclusion: Awareness about the availability of labour epidural analgesia services needs to be improved, as a majority of the parturient was keen to avail epidural analgesia after the information about its availability was provided.

Keywords: awareness, labour epidural analgesia, perception

\section{INTRODUCTION}

Labour pain is one of the most painful physiological condition and medically accepted conditions known to human beings. It is an unavoidable physiological and natural phenomenon that a pregnant woman undergoes. ${ }^{1,2}$ Maternal request is a sufficient indication for offering pain relief during labour. Labour analgesia is required in parturient with certain risk factors like heart disease, diabetes, and hypertension. ${ }^{3,4}$ Epidural procedure involves an administration of analgesia through the catheter placed into the epidural space which blocks the nerves that transmit pain and temporarily causes pain relief. ${ }^{3}$ The epidural administration of drugs was initiated in 1884, when Corning, a New York neurologist, administered cocaine through a needle inserted in between thoracic level 11-12. Epidural analgesia for labour was first practiced in 1970 s. First epidural catheter was used in 1931. ${ }^{5}$

Pain during childbirth is a wellknown cause of dissatisfaction amongst women in labour. Relieving pain during childbirth is an important concern for women and benefits in terms of pain relief by epidural analgesia are well recognized. Epidural anaesthesia is widely used in the developed countries. Labour epidural analgesia is said to provide adequate pain relief in $90 \%$ to $95 \%$ of the cases. ${ }^{6}$ There is increased use 
of labour epidural service globally in recent times and LEA (labor epidural analgesia) is considered as gold standard procedure $(50-90 \%)$ in most of the developed countries however, the use of epidural analgesia is $1.3 \%$ in developing countries. ${ }^{7}$

Epidural analgesia for labour pain was launched in Bhutan on $7^{\text {th }}$ February 2016. The rate of epidural labour analgesia over the past four years from 2016 through 2019 were $1.8 \%, 2.2 \%, 3.8 \%$ and $2.8 \%$ respectively. Thus, the study on labor analgesia was chosen for its objective.

\section{METHODS}

This was an observational cross-sectional study. The study was conducted at the antenatal clinic at Jigme Dorji Wangchuck National Referral Hospital, Thimphu, Bhutan. Study participants included pregnant women visiting the antenatal clinic during 2 nd and $3^{\text {rd }}$ trimester. All parturients with history of past caesarean section, multiple pregnancies, differently abled pregnant women (mentally challenged, deaf and dumb who cannot efficiently participate in this study), past caesarean section and multiple pregnancy were excluded. Sample size calculated from the past report of $67 \%$ antenatal booking. ${ }^{8,9}$

Data were collected by using an intervieweradministered questionnaire. The interview was conducted at a separate counter shielded by a screen where privacy of the interview was ensured. The interviewers were given a training to maintain the consistency of interpretation of the questionnaire. Data duplication was avoided by excluding the parturient who had already participated in this study by asking their socio demographic profile.

Data were collected on paper-based (interviewer semi structured) questionnaire and stored in a secured locker. The data were entered into EpiData 3.1 and analysed in EpiData Analysis V2.2.2.183.

Descriptive statistics such as percentages were used to describe the basic socio-demographic details. Frequency and percentage were used to describe the demographic characteristics of each group. Pain score was categorised as no pain (VAS score 0), mild (VAS 1 to 3 ), moderate (VAS 4 to 6 ), severe (VAS 7 to 10 ).

\section{RESULTS}

Out of 461 parturients who were willing to participate in this research, 11 parturients did not fill all the questionnaires. Therefore, the actual parturient who participated in this study was 450 . From 448 parturient, only 27 (six percent) participants were less than 20 years old and only four $(0.9 \%)$ parturient were above 40 years of age. Majority of the participants $(48.2 \%)$ were educated up to $9-12^{\text {th }}$ standard. Only $12.2 \%$ of the participants were illiterate. Around $48.8 \%$ parturients were housewives and the rest were employed either in government or private sectors. Majority (57\%) belonged to middle income group having an average monthly income of national currency 10001 to 50000 and $7 \%$ earning less than 1000 . Most of them $(82.2 \%)$ were from urban areas; and $17.2 \%$ from rural area. [Table-1]

Table-1: Socio-demographic characteristics of pregnant women visiting antenatal clinic in National Referral Hospital, 2018 (N=450)

\begin{tabular}{cllll}
\hline & Characteristics & \multicolumn{1}{c}{$\mathrm{n}$} & \multicolumn{1}{c}{$\%$} & $\sum$ \\
\hline \multirow{2}{*}{ Age } & $\leq 20$ & 27 & $(6.0)$ & \\
group & $21-30$ & 319 & $(71.2)$ & 448 \\
& $31-40$ & 98 & $(21.9)$ & \\
Level & $>40$ & 4 & $(0.9)$ & \\
of & Non-formal & 12 & $(2.7)$ & \\
Edu- & Class PP - VIII & 63 & $(14.2)$ & 444 \\
cation & Class IX - XII & 214 & $(48.2)$ & \\
2 & $\geq$ Diploma/degree & 101 & $(22.8)$ & \\
Occu- & Housewife & 215 & $(48.8)$ & \\
pation & Corporate/Private & 166 & $(37.6)$ & 441 \\
3 & Government & 60 & $(13.6)$ & \\
& $<1000$ & 31 & $(7.0)$ & \\
& $1,001-10,000$ & 138 & $(30.9)$ & \\
In- & $10,001-50,000$ & 254 & $(57.0)$ & 446 \\
come & 50,001 - 100,000 & 19 & $(4.3)$ & \\
& $>100,000$ & 4 & $(0.9)$ & \\
Resi- & Urban & 370 & $(82.8)$ & \multirow{2}{*}{4} \\
dence & Rural & 77 & $(17.2)$ & 447 \\
& & & & \\
\hline
\end{tabular}

Approximately $54.9 \%$ were primigravida and $45.1 \%$ were multigravida. Of the multigravida respondents, $49.7 \%$ had severe labour pain during their last child birth. Majority of parturients $(77.9 \%)$ did not received any pain relief during their last child birth , of which $50 \%$ of parturients received pain relief method in the form of injection and only $5.9 \%$ received epidural analgesia. Only $(30.3 \%)$ of the participants were fully satisfied with their pain relief method in last child birth and $15.2 \%$ were not at all satisfied. [Table-2] 
Table-2: Characteristics and information regarding previous pregnancy among pregnant women visiting antenatal clinic in National Referral Hospital, 2018(N=450)

\begin{tabular}{|c|c|c|c|c|}
\hline \multicolumn{2}{|c|}{ Characteristics } & $\mathrm{n}$ & $\%$ & $\sum$ \\
\hline \multirow{2}{*}{ Gravidity $^{1}$} & Primi gravida & 242 & 54.9 & \multirow{2}{*}{441} \\
\hline & Multigravida & 199 & 45.1 & \\
\hline \multirow{2}{*}{$\begin{array}{l}\text { Place of } \\
\text { delivery }^{2}\end{array}$} & Hospital & 187 & 94.4 & \multirow[t]{2}{*}{198} \\
\hline & Home & 11 & 5.6 & \\
\hline \multirow{3}{*}{ Pain level $^{3}$} & $1-3$ & 22 & 11.2 & \multirow{3}{*}{197} \\
\hline & $4-6$ & 77 & 39.1 & \\
\hline & $7-10$ & 98 & 49.7 & \\
\hline \multirow{2}{*}{ Analgesia $^{4}$} & Yes & 37 & 18.6 & \multirow{2}{*}{192} \\
\hline & No & 155 & 77.9 & \\
\hline \multirow{4}{*}{$\begin{array}{l}\text { Pain relief } \\
\text { method }^{5}\end{array}$} & Oral & 3 & 8.8 & \multirow{4}{*}{34} \\
\hline & Epidural analgesia & 2 & 5.9 & \\
\hline & Injection/IV & 17 & 50.0 & \\
\hline & Others & 12 & 35.3 & \\
\hline \multirow{3}{*}{$\begin{array}{l}\text { Satisfaction } \\
\text { with pain } \\
\text { relief } \\
\text { method }^{6}\end{array}$} & Not at all & 5 & 15.2 & \multirow{3}{*}{33} \\
\hline & Somewhat satisfied & 18 & 54.6 & \\
\hline & Fully Satisfied & 10 & 30.3 & \\
\hline & $\begin{array}{l}{ }^{2} \text { Missing }=1 ;{ }^{3} \mathrm{Mis} \\
{ }^{5} \mathrm{Missing}=3 ;{ }^{6} \mathrm{Mis}\end{array}$ & $\begin{array}{l}=2 ; \\
=4\end{array}$ & & \\
\hline
\end{tabular}

Majority (61.4\%) of the participants knew that labour epidural services were available in JDWNRH

and $37.5 \%$ of parturient got information through media. Amongst the $38.6 \%$ of parturients who did not know about availability of epidural labour analgesia, $76.5 \%$ were willing to accept labour epidural analgesia, although $23.5 \%$ still refused after receiving information about labour epidural analgesia. Out of those declined, 11 women $(28.2 \%)$ thought that birth was a natural process and rest of the parturients had other misconceptions. Only $9.2 \%$ of the women thought that they should talk to obstetrician to avail this service and only $11.6 \%$ women thought they should talk to Anesthesiologist to vail the epidural service and majority of the women $33.7 \%$ didn't know whom they ask for the labour epidural analgesia. Most parturients (83.4\%) did not know that some women are not suitable for labour epidural analgesia. [Table-3]

Table-3: Knowledge on labour epidural analgesia services among pregnant women visiting antenatal clinic in national referral hospital, $2018(\mathrm{~N}=450)$

\begin{tabular}{|c|c|c|c|c|}
\hline \multirow{3}{*}{ Availability of LEA ${ }^{1}$} & Characteristics & $\mathrm{n}$ & $\%$ & Total \\
\hline & Yes & 275 & $(61.4)$ & \multirow{2}{*}{448} \\
\hline & No & 173 & $(38.6)$ & \\
\hline \multirow{5}{*}{ Source of knowledge ${ }^{2}$} & Family/relatives & 58 & $(21.1)$ & \multirow{5}{*}{275} \\
\hline & Friends & 72 & $(26.2)$ & \\
\hline & Media (television, radio, newspapers, social media) & 103 & $(37.5)$ & \\
\hline & Health worker & 38 & $(13.8)$ & \\
\hline & Hospital pamphlet (paper information) & 4 & $(1.5)$ & \\
\hline \multirow{3}{*}{ Willing for LEA } & Yes & 130 & $(76.5)$ & \multirow{3}{*}{170} \\
\hline & No & 40 & $(23.5)$ & \\
\hline & Fear of complication & 9 & $(23.1)$ & \\
\hline \multirow{4}{*}{ Cause for non-willing } & Cannot decide on own & 9 & $(23.1)$ & \multirow{4}{*}{39} \\
\hline & Birthing is natural process & 11 & $(28.2)$ & \\
\hline & Belief that mother has to suffer & 6 & $(15.4)$ & \\
\hline & Others (religious belief, social, family) & 4 & $(10.3)$ & \\
\hline \multirow{5}{*}{ Whom to ask for $\mathrm{LEA}^{4}$} & Nurse & 123 & $(27.6)$ & \multirow{5}{*}{445} \\
\hline & General Doctor & 79 & $(17.8)$ & \\
\hline & Specialist Obstetrician & 41 & $(9.2)$ & \\
\hline & Specialist Anesthesiologist & 52 & $(11.7)$ & \\
\hline & Don't know & 150 & $(33.7)$ & \\
\hline \multirow{2}{*}{ Know who can't take LEA ${ }^{5}$} & Yes & 74 & $(16.6)$ & \multirow{3}{*}{445} \\
\hline & No & 371 & $(83.4)$ & \\
\hline \multirow{4}{*}{ Timing of service ${ }^{6}$} & At any time of the day ( 24 hours) & 107 & $(24.2)$ & \\
\hline & Only during weekdays & 25 & $(5.6)$ & \multirow{3}{*}{443} \\
\hline & Only when specialist anaesthesiologist is available & 58 & $(13.1)$ & \\
\hline & Don't know & 253 & $(57.1)$ & \\
\hline
\end{tabular}


A total of $57.3 \%$ of respondents had severe fear about labour pain. Most $85.2 \%$ thought that epidural labour analgesia was a good method of pain relief in labour but only $67 \%$ were willing to accept it for their current pregnancy. However, $86.6 \%$ would recommend epidural labour analgesia as an option of pain relief to other pregnant women. [Table-4]

Table-4: Perception about labour pain and LEA among pregnant women visiting antenatal clinic in national referral hospital, $2018(\mathrm{~N}=450)$

\begin{tabular}{|c|c|c|c|c|}
\hline \multicolumn{2}{|c|}{ Characteristics } & $\mathrm{n}$ & $\%$ & $\sum$ \\
\hline \multirow{3}{*}{$\begin{array}{l}\text { Level of fear } \\
\text { about labour } \\
\text { pain }^{1}\end{array}$} & Mild pain & 47 & 10.5 & \multirow{3}{*}{447} \\
\hline & Moderate pain & 144 & 32.2 & \\
\hline & Severe pain & 256 & 57.3 & \\
\hline \multirow{4}{*}{$\begin{array}{l}\text { Level of fear } \\
\text { about deliv- } \\
\text { ery compli- } \\
\text { cations } 1\end{array}$} & No fear & 2 & 0.5 & \multirow{4}{*}{447} \\
\hline & Mild Fear & 37 & 8.3 & \\
\hline & Moderate fear & 129 & 28.9 & \\
\hline & Severe fear & 279 & 62.4 & \\
\hline \multirow{2}{*}{$\begin{array}{l}\text { LEA a good } \\
\text { method for } \\
\text { pain relief }{ }^{2}\end{array}$} & Yes & 380 & 85.2 & \multirow{2}{*}{446} \\
\hline & No & 66 & 14.8 & \\
\hline \multirow{2}{*}{$\begin{array}{l}\text { Willing to } \\
\text { accept LEA }\end{array}$} & Yes & 294 & 67.0 & \multirow{2}{*}{439} \\
\hline & No & 145 & 33.0 & \\
\hline \multirow{2}{*}{$\begin{array}{l}\text { Recommend } \\
\text { LEA }^{2}\end{array}$} & Yes & 386 & 86.6 & \multirow{2}{*}{446} \\
\hline & No & 60 & 13.5 & \\
\hline
\end{tabular}

${ }^{1}$ Missing $=3 ;{ }^{2}$ Missing $=4 ;{ }^{3}$ Missing $=11$

\section{DISCUSSION}

Severe labour pain is experienced by most of the women especially primigravida. ${ }^{10}$ Women suffer pain despite the availability of analgesia labour services. Many parturients are using epidural analgesia as a pain relieving during labour. ${ }^{4}$ In the current study, $61.4 \%$ of the study participants had awareness about availability of labour epidural services. The awareness of labour epidural analgesia differ from the study done in India and Nigeria (9.5\% and $27 \%$ respectively). ${ }^{4,11}$ But the findings in this study was similar to that of study done in Australia. $^{12}$

In the current study, most had heard about it through the media (37.5\%). In a similar study from Nigeria, most of the women had gained knowledge of pain relief from previous experience or from friends and relatives, with only a few gaining knowledge from media and textbooks. ${ }^{6}$

When parturients were asked whether they were willing to accept labour epidural analgesia for their current pregnancy after giving information about LEA to those who did not hear about the LEA, out of 173 women, majority $(76.5 \%)$ parturients were willing to accept labour epidural analgesia and few $(23.5 \%)$ parturients thought that giving birth is a natural process and many had misconceptions and fear which was consistence with the study done by $\mathrm{F}$ Ibach et al. ${ }^{13}$ This discrepancy in the level of awareness and willingness to accept labour epidural analgesia could be attributed to the misconceptions and fears associated with labour epidural analgesia. This was similar to the study done in Nigeria. ${ }^{11}$ Studies conducted even in developed countries have shown similar misconceptions related to epidural. ${ }^{11,14}$ A study done in India also found that most of the parturient think that epidural analgesia results in permanent backache, had a detrimental effect on the baby, prolongs labour and ends up in caesarean section or instrumental delivery. ${ }^{1}$

The fact that the majority of participants were willing to accept epidural labour analgesia after knowing about its availability indicates that we are lagging behind in the area of dissemination of this valuable information. This study demonstrated that though many parturient are aware of LEA service and majority of them were educated they still shave unfounded fears and misconception about LEA. An awareness campaign can be done by trained nurse or health workers who have adequate knowledge on LEA and help the parturients over decision making after receiving proper information from proper source. ${ }^{10-14}$

The perception towards labour may be influenced by women's upbringing, culture, age or peer pressure. ${ }^{4}$ In Some studies the past experience and expected labour pain were graded as severe pain which was similar to this current study. ${ }^{15-16}$ It has been observed that in developing countries like India and South Africa antenatal education may be of greater importance, as many partuients may be less educated and their ability to seek and access information is limited; and they dependent on education provided by relatives, friends and health workers. Participants identified pain relief method as injections. This choice is most likely because injections may be the only form of pain relief they 
know or have experienced. Inspite of using pharmacological method, parturients were dissatisfied with labour analgesia which was consistent with other studies. ${ }^{4}$

The result of this study observed that only $67 \%$ parturients were willing to accept epidural; however majority $(86.6 \%)$ would recommend to other parturients. This discrepancy could not be explained by this study; however, it can be postulated that it can be due to poor decision making, ineffective analgesia during their previous pregnancy and lack of epidural service in other part of country. ${ }^{15,17}$ Similar findings are reported by Khaskheli at al. ${ }^{18}$

Use of epidural analgesia varies considerably with the women's social demographic profile and specialty of the physicians involved in managing the labour. A study found that the race and lower socioeconomic status were seen as reasons for refusal of epidural analgesia for labour; while parturient with jobs, higher income, higher educational level and knowledge about epidural were variably associated with acceptance of labour epidural analgesia. ${ }^{19}$

The degree of subjective feel of labour pain, number of previous childbirth and a high level of education were associated significantly with the acceptance of epidural labor analgesia. ${ }^{15,19}$ In general, this shows that there is lack of knowledge or awareness regarding in all level of society.

Awareness amongst the pregnant women can be created by giving proper and full information about the role epidural analgesia in painless labour as most of the women has little or no confidence in labour pain..$^{10,20}$

\section{CONCLUSIONS}

Labour epidural is one of the most effective methods of pain relief in labour. Many women in this study expected the severe pain during labour; and few opposed the idea of relieving pain due to misconceptions that indicates inadequate information regarding the epidural analgesia. Awareness about the availability of LEA services needs to be improved, as a majority of the parturient was keen to avail epidural analgesia after the information about its availability was provided. The involvement of obstetricians, anaesthesiologist and antenatal nurses is crucial in educating parturient to raise and clear mis-perceptions so that more parturients opt for epidural labour analgesia.

\section{REFERENCES}

1. Barakzai A, Haider G, Yousuf F, Haider A, Muhammad N. Awareness of women regarding analgesia during labour. J Ayub Med Coll Abbottabad [Internet]. 2010;22(1):73-5.

2. Ohel G, Gonen R, Vaida S, Barak S, Gaitini L. Early versus late initiation of epidural analgesia in labor: Does it increase the risk of cesarean section? A randomized trial. Am J Obstet Gynecol. 2006;194(3):600-5.

3. Anim-Somuah M, Smyth RMD, Cyna AM, Cuthbert A. Epidural versus non-epidural or no analgesia for pain management in labour. Cochrane Database Syst Rev. 2018;2018(5).

4. Naithani, Bharwal P, Chauhan SS, Kumar D, Gupta S, Kirti. Knowledge, attitude and acceptance of antenatal women toward labor analgesia and caesarean section in a medical college hospital in India. J Obstet Anaesth Crit Care [Internet]. 2011;1(1):13.

5. Waghchoure ND, Sable T. Woman's and nurses knowledge and awareness regarding epidural analgesia. Scholars J App Med Sci..2016;4:3266-8.

6. Ezeonu PO, Anozie OB, Onu FA, Chidi E, Mamah JE. Perceptions and practice of epidural analgesia among women attending antenatal clinic in FETHA. Int $\mathrm{J}$ WOmens Health. 2017;905-11.

7. Parajian T, Angle P, Kurtz Landy CM, Djordjevic. A snapshot of women's attitudes and preferences toward labor epidural analgesia and cesarean delivery. Int J Anesth Res. 2016;4:200-7.

8. Dorji T, Das M, Van Den Bergh R, Oo MM, Gyamtsho S, Tenzin K, et al. "if we miss this chance, it's futile later on" - Late antenatal booking and its determinants in Bhutan: A mixed-methods study. BMC Pregnancy Childbirth. 2019;19(1):1-13.

9. Jigme Dorji Wangchuck National Referral Hospital. Standard operating procedure: Department of Obstetrics and Gynecology. 2017;1-69.

10. Shidhaye RV, Galande M, Bangal VB, Smita J, Shidhaye UR. Awareness and attitude of Indian pregnant women towards labour analgesia. Anaesthesia, Pain Intensive Care. 2012;16(2):131-6.

11. Okojie NQ, Isah EC. Perception of Epidural 
Analgesia for Labour among Pregnant Women in a Nigerian Tertiary Hospital Setting. J West African Coll Surg. 2014;4(4):142-62.

12.Henry A, Nand SL. Women's antenatal knowledge and plans regarding intrapartum pain management at the Royal Hospital for Women. Aust New Zeal J Obstet Gynaecol. 2004;44 (4):314-7.

13. Ibach F, Dyer RA, Fawcus S, Dyer SJ. Knowledge and expectations of labour among primigravid women in the public health sector. South African Med J. 2007;97(6):461-4.

14. Karn S, Yu H, Karna S, Chen L and Qiao D Y. Women's awareness and attitudes towards labor analgesia influencing practice between developed and developing Countries. Advances in reproductive sciences. 2016;(May):46-52.

15. Mugambe JM, Nel M, Hiemstra LA, Steinberg WJ. Knowledge of and attitude towards pain relief during labour of women attending the antenatal clinic of Cecilia Makiwane Hospital, South Africa. South African Fam Pract. 2007;49 (4):16.
16. Almushait M, Ghani RA. Perception toward Non-Pharmacological Strategies in Relieving Labor Pain: An Analytical Descriptive Study. J Nat Sci Res [Internet]. 2014;4(2):5-12.

17. Toledo P, Sun J, Peralta F, Grobman WA, Wong CA, Hasnain-Wynia R. A qualitative analysis of parturients' perspectives on neuraxial labor analgesia. Int J Obstet Anesth [Internet]. 2013;22(2):119-23.

18. Khaskheli M, Baloch S. Subjective pain perceptions during labour and its management. J Pak Med Assoc. 2010;60(6):473-6.

19. Sheiner E, Sheiner EK, Shoham-Vardi I, Gurman GM, Press F, Mazor M, et al. Predictors of recommendation and acceptance of intrapartum epidural analgesia. Anesth Analg. 2000;90 (1):109-13.

20. Srivastava A, Avan BI, Rajbangshi P, Bhattacharyya S. Determinants of women's satisfaction with maternal health care: A review of literature from developing countries. BMC Pregnancy Childbirth. 2015;15(1):1-12. 